\title{
Dysfunction of the peripheral and central auditory pathway in patients with type 1 diabetes mellitus
}

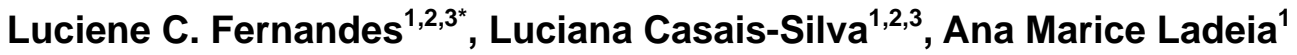 \\ ${ }^{1}$ Bahiana School of Medicine and Public Health, Bahia, Brazil; ${ }^{*}$ Corresponding Author: luenefernandes@gmail.com \\ ${ }^{2}$ Health Sciences Institute, Federal University of Bahía, Bahia, Brazil \\ ${ }^{3}$ Department of Science of Life, State University of Bahia, Bahia, Brazil
}

Received 8 October 2011; revised 9 November 2011; accepted 28 November 2011

\begin{abstract}
Although auditory alterations are not a typical symptom of diabetes mellitus (DM), they can occur in patients with type $1 \mathrm{DM}$. The findings of previous studies are controversial, because the frequency and degree of hearing loss varies, and quite often alterations are still subclinical. The typical test used to detect and manage hearing loss is the audiogram, but this test alone is only capable of detecting alterations due to injury of the inner hair cells and/or alterations in the central auditory pathway. However, auditory alterations resulting from a dysfunction that is still subclinical are only able to be detected through electrophysiological auditory tests, such as the otoacoustic emissions (OAE) and the auditory brainstem response (ABR) tests. Thus, the purpose of this paper is to review the studies that utilize the OAE and ABR tests, and to verify if the dysfunction is cochlear and/or neural in patients with type $1 \mathrm{DM}$. The findings of this review demonstrate that patients with type $1 \mathrm{DM}$ can have auditory alterations stemming from a central cochlear origin. Following this finding, early diagnosis is very important in order to implement preventative treatments and initiate therapy.
\end{abstract}

Keywords: Diabetes Mellitus; Brainstem Auditory Evoked Potentials; Otoacoustic Emission

\section{INTRODUCTION}

The American Diabetes Association (2010) [1] defines diabetes mellitus (DM) as a group of metabolic diseases characterized by hyperglycemia, which is a result of alterations in the secretion and/or action of insulin. DM can be divided into four categories: The first - type 1involves an absolute deficiency in the secretion of insulin.
The second - type 2-involves a combination of resistance to the action of insulin The third main type-type 3 -is often referred to as gestational diabetes, when glucose intolerance is detected for the first time during pregnancy. The fourth group entails the remaining varieties as outlined by the etiology.

Despite the regular use of insulin, patients with type 1 DM frequently present instances of hyperglycemia as well as hypoglycemia, which can cause a number of complications. These include: retinopathy-alterations in the retina characterized by vascular complications; neuropathy - gradual degeneration of nerve fibers of the axons; microalbuminuria - presence of the protein albumen in urine [2]; and further complications may include myocardium infarction and cerebral vascular accidents [3].

Although auditory alterations are not a typical symptom, they can occur in patients with type $1 \mathrm{DM}$. These alterations are normally related to structures of the inner ear (cochlea), including Corti's organ and structures of the central auditory pathway, from the nerve until the auditory cortex. In Corti's organ, there are outer and inner hair cells. The outer hair cells are responsible for amplification and the inner hair cells are responsible for mechanical-electrical transduction of sound. This mechanical-electrical transduction is the transmission of sound that initially occurs within a mechanical system, until contacting the inner hairs cells, when it is changed into electric potential that will lead the auditory information through the central nervous system. Alterations in these inner structures are called sensorineural, and the examination best known for identifying possible hearing loss is the audiogram [4].

The audiogram is a psychoacoustic test that determines the subject's minimum sensitivity threshold for a sound with a determined frequency and intensity (tonotopy). The test is able to detect alterations in the cochlea (sensorial), from the lowest (base) frequencies to the highest (apex) frequencies, as well as alterations in the neuronal synchrony. 
Studies of type 1 DM utilizing the audiogram are controversial because the frequency of hearing loss presented in the findings of these studies varies from 0 until $80 \%[5,6]$. However, many authors have observed that there is a greater prevalence of sensorineural hearing loss in the population with type $1 \mathrm{DM}$ in comparison to the group without the disease $[7,8]$.

In accordance with literature, the type of hearing loss typically found in DM is sensorineural, of gradual and bilateral character, and reaching higher frequencies [9-11]. However, some authors have found low [9] and middle frequency $[10,12]$ hearing loss and one found a case of sudden hearing loss [13].

The possible etiopathogeny of these alterations is not completely defined yet, as they may be due to early neuropathy, angiopathy or metabolic complications due to the hyperactivity of free radicals resultant of the nonenzymatic glication [8].

The audiogram is only capable of detecting alterations occurring from injury to the inner hair cells and/or alterations in the central auditory pathway. However, auditory alterations resulting from a dysfunction, that is, still subclinical alterations, are only able to be detected through the electrophysiological auditory tests. These assessments include the otoacoustic emissions (OAE) and auditory brainstem response (ABR) tests. These two tests are also capable of determining the location of the injury, with OAE distinguishing the sensorial alterations, and ABR distinguishing the neural alterations. Thus, in most of the cases, the auditory alterations occurring from type $1 \mathrm{DM}$ are not detected in conventional auditory tests, such as the audiogram, because it does not possess the necessary sensitivity and specificity to detect all types of alterations occurring from this pathology.

\section{COCHLEAR DYSFUNCTION IN TYPE 1 DM}

The advent of the OAE is the newest method for the identification of complications in sensorineural hearing loss. The assessment is objective, relatively simple, fast, and non-invasive [14]. This test is very useful in identifying subclinical alterations in the cochlear micromechanics, and more specifically in evaluating the functioning of the outer hair cells.

OAE tests can be spontaneous or evoked, and can be of the transient type (TOAE) or the distortion product type (DPOAE). The TOAE evaluates the cochlea as a whole, and is restricted from 1 to $5 \mathrm{kHz}$, frequencies which are only detected in subjects with normal auditory thresholds. The DPOAE evaluates specific parts of the cochlea and varies from 0.5 to $8 \mathrm{kHz}$, frequencies which are detected in subjects with normal hearing and mild hearing loss. The evaluation is conducted through iden- tifying the presence or absence of OAEs and monitoring their amplitude.

In all the studies presented in Table 1 (except Ugur et al. (2009) [15]) the presence of lower amplitude can be observed in patients with type $1 \mathrm{DM}$. This suggests that even in patients with normal auditory thresholds, the metabolic changes caused by the disease can modify the micromechanics of the inner ear, generating an early subclinical finding. This data can be confirmed through histopathological studies of the inner ear that demonstrate the following: a thickening of the capillary walls of the vascular stria - epithelial stratification that forms the endolymphatic edge of cochlear sac, which is important in the production of ionic gradients and of the endocochlear potential; peri and endolymphatic hemorrhaging; reduction in the number of fibers of the spiral plate - the bone plate that extends out from the modiolus to inside the cochlear duct, forming part of the structure that divides the superior vestibule slope and the inferior tympanic slope; degenerative changes in Corti's organ and reduction of the outer hair cells $[16,17]$.

All of the studies that used the transient type OAE (TOAE) test demonstrated the same reduction in the amplitude of patients with DM, except in the study of Erdem et al. [18] In this study, Erdem et al. demonstrated that the auditory thresholds could present mild hearing loss (30dBNA), which would imply a more accentuated alteration period, and which could render the TOAE test less sensible. However, studies of other pathologies demonstrate that TOAE tests are sufficiently sensible in early auditory alterations of the inner ear [19].

All the studies that used DPOAE demonstrated a reduction in the amplitude of OAE in patients with DM, but due to the specificity of frequency of this test, the studies are divergent on which frequencies were modified. In studies with subjects up to 33 years of age the middle frequencies prevailed, and after this age higher frequencies were more greatly reduced in DM patients. This data can also be related to aging, and many authors state that in patients with DM this relatively early hearing loss may in fact be age-associated [20]. However, in the population that is still too young to have age-associated hearing loss, manifestation of type $1 \mathrm{DM}$ metabolic alteration would be more common in the low and middle frequencies.

Thus, considering that the audiogram (which is typically used for evaluation of hearing loss) does not detect the observed early alterations in patients with DM, the TOAE would be a sensible test for early detection, while the DPOAE test would be more specific to the frequencies affected in accordance with the advance of age.

The only study in which OAEs were not reduced, but rather were increased, included younger patients with type 1 DM [15]. This study demonstrated the effect of 
Table 1. Studies with type 1 diabetes mellitus using the tests of transient (TOAE) and distortion product (DPOAE) otoacoustic emissions.

\begin{tabular}{|c|c|c|c|c|}
\hline Authors & Number of Patients & Average age & Audiogram & Results \\
\hline Ugur et al. 2009 [15] & 30 & 11 & Normal & $\begin{array}{l}\text { TOAE trend }>\text { amplitude and DPOAE with no } \\
\text { difference; Effect of suppression }<\text { in DM }(2-4 \mathrm{kHz}) \text {; } \\
\text { TOAE - negative correlation with } \mathrm{Hb} \text {; no correlation } \\
\text { to effect of suppression and } \mathrm{Hb}\end{array}$ \\
\hline Alborch et al. 1998 [23] & 20 & 25 & normal & $\begin{array}{l}\text { TOAE }<\text { amplitude and DPOAE with }<\text { amplitude } \\
\text { in low and middle frequencies }\end{array}$ \\
\hline Di Leo et al. 1997 [24] & 48 & 28 & normal & $\begin{array}{l}\text { TOAE and DPOAE }<\text { amplitude and correlation } \\
\text { with neuropathy; without correlation } \mathrm{Hb} \text {, duration } \\
\text { of disease and motor and sensorial conduction. }\end{array}$ \\
\hline Dabrowski et al. 2011 [25] & 31 & 29.1 & normal & $\begin{array}{l}<\text { amplitude TOAE, negative correlation with age, } \\
\text { without correlation to duration of disease and } \\
\text { metabolic control. }\end{array}$ \\
\hline Ottaviani et al. 2002 [26] & 60 & 31 & normal & $\begin{array}{l}\text { TOAE and DPOAE < amplitude. Absence of TOAE } \\
\text { only DM and in the DPOAE }>\text { significance in } \\
\text { middle frequencies; without } \mathrm{Hb} \text {, insulin, duration of } \\
\text { disease, age, retinopathy and neuropathy correlation. }\end{array}$ \\
\hline Lisowska et al. 2001 [5] & 42 & 33 & normal & $\begin{array}{l}\text { DPOAE < amplitude in DM, mainly middle and } \\
\text { high frequencies; without microangiopathy } \\
\text { correlation. }\end{array}$ \\
\hline Di Nardo et al. 1998 [22] & 47 & 33 & normal & $\begin{array}{l}\text { TOAE and DPOAE ( } 1 \text { a } 5 \mathrm{kHz})<\text { amplitude in DM } \\
\text { with neuropathy; DPOAE ( } 3 \text { a } 5 \mathrm{kHz})<\text { amplitude } \\
\text { in DM without neuropathy }\end{array}$ \\
\hline Erdem et al. 2003 [18] & 21 & 48 & to $30 \mathrm{dBNA}$ & $\begin{array}{l}\text { TOAE without difference; DPOAE }<\text { amplitude in } \\
\text { DM in frequencies of } 4 \mathrm{kHz} \text {. }\end{array}$ \\
\hline Park et al. 2001 [21] & 18 & 54 & normal & $\begin{array}{l}\text { DPOAE }<\text { amplitude in DM, mainly } 8 \mathrm{kHz} \text {; latency } \\
>\text { in DM except in } 1 \mathrm{kHz} \text {; correlation of amplitude } \\
\text { of the DPOAE with } \mathrm{Hb} \text { and without latency } \\
\text { correlation to } \mathrm{Hb} \text { and retinopathy }\end{array}$ \\
\hline
\end{tabular}

suppression, which incorporates a test that uses OAEs, in conjunction with a competitive noise. This process activates the efferent system through the olivocochlear medial pathway, which has the objective of controlling the entrance of the sound through the afferent system, perfecting the sound characteristics for interpretation of acoustic information for the auditory cortex. This effect of suppression was found to be worse in younger subjects with type $1 \mathrm{DM}$ than in the group of subjects without the disease. This data explains the increase of OAE, which due to the dysfunction of this system, can be seen as an early central manifestation resulting from metabolic changes occurring in patients with type 1DM.

Regarding associated comorbitities, Ugur et al. 2009 [15] verified a negative correlation between the amplitude of the TOAE and the values of glycated hemoglobin in younger type $1 \mathrm{DM}$ patients. The study conducted by Park et al. 2001 [21] of an older patient population observed a positive correlation between glycated hemoglobin and DPOAE. Kakarlapudi et al. [8] observed a greater prevalence of sensorineural hearing loss in type 1 DM patients without control of the disease. This data demonstrates the importance of metabolic control and the necessity of a multicriteria choice of audiological examinations for earlier detection of auditory alterations.

The study conducted by Di Nardo et al. 1998 [22] demonstrated that it was possible to verify a relationship between neuropathy and the amplitude of TOAE, as well as with the frequencies from 1 to $5 \mathrm{kHz}$ of the DPOAE. However, in the group without neuropathy the correlation only occurred in frequencies from 3 to $5 \mathrm{kHz}$ of DPOAE. This suggests that in patients with neuropathy the peripheral auditory alterations can be more accentuated, affecting not only higher but also middle frequencies, and can be detected in the TOAE, which did not occur in the group without neuropathy. Further, the studies are very diverse and a comparison of the studies would be difficult, as would be establishing any type of consensus on the associations between type $1 \mathrm{DM}$ and other comorbidities.

\section{NEURAL DYSFUNCTION IN TYPE 1 DM}

The evaluation of the central auditory pathway can be used to test the auditory brainstem response, which evaluates the auditory nerve and the structures of the 
brainstem. This test basically evaluates the absolute latency of waves, which is the time needed for the stimulation to initiate the auditory potential in a determined structure. Further, the test evaluates intervals - which are the time necessary for the electric potential to pass from one structure to another.

Table 2 presents data regarding auditory brainstem response (ABR), which demonstrates that in almost all of the studies there is an increase in at least one latency time. This data confirms the studies with OAE, because the delay in the latency time is generally associated to peripheral dysfunction.

With regard to intervals, the majority of the studies demonstrate that some intervals are increased, which indicates that a central auditory component also exists which is resultant of the metabolic alterations from type 1 DM. Regarding an association of the alterations of $\mathrm{ABR}$ and comorbidities, it was possible to verify that in the majority of studies, there was some degree of association between them. Ugur et al. 2009 [15] observed that the time of treatment contributed to worse ABR re- sponses, demonstrating that control of the disease is fundamental into preventing auditory alterations. The study by Seidl et al. [27] presented similar findings, demonstrating that the duration of the disease and severe episodes of hyperglycemia affect the results of the ABR. Ottaviani et al. [26] and Toth el al. [28] observed a correlation between ABR and neuropathy, as well as with cardiovascular autonomic neuropathy. However, similar to studies with OAE, there is no consensus between these studies, which is probably due the protocols used and the distinct differences between them.

With regard to patient age and possible alterations of the ABR, there was no difference between studies, as these criteria were present in the same way in the studies with younger and older populations. However, Durmus et al. [29] observed a tendency of correlation in patients over 30 years of age.

In terms of gender, Pudar et al. [20] verified that male patients present absolute latencies and longer intervals than female patients with type $1 \mathrm{DM}$, in comparison to subjects without the disease.

Table 2. Studies of type 1 diabetes mellitus using the auditory brainstem response (ABR) test.

\begin{tabular}{|c|c|c|c|c|}
\hline Authors & Number of Patients & Average age & Audiogram & Results \\
\hline Niedzielska e Katska [30] & 37 & $6-18$ & normal & $\begin{array}{l}\text { Absolute latencies and intervals }>\text {, except in the } \\
\text { interval III-V; without duration of disease } \\
\text { correlation; duration of treatment ( }<3 \text { years } \\
\text { worse results) }\end{array}$ \\
\hline Seidl et al.1996 [27] & 53 & 11 & normal & $\begin{array}{l}\text { Absolute Latency }(\mathrm{V}) \text { and intervals }>\text { in } \mathrm{DM}>2 \\
\text { years duration of disease; correlation to severe } \\
\text { episodes of hyperglycemia. }\end{array}$ \\
\hline Pessin et al. 2008 [31] & 40 & 15.8 & normal & $\begin{array}{l}\text { Interval I-III >; without correlation to duration of } \\
\text { disease and glycemic control. }\end{array}$ \\
\hline Durmus et al. 2004 [29] & 17 & 24.3 & normal & $\begin{array}{l}\text { Absolute Latencies and intervals (I-V e III-V) >; } \\
\text { trend correlation with age (over } 30 \text { years old); } \\
\text { without correlation to duration of disease, gender } \\
\text { and neuropathy. }\end{array}$ \\
\hline Pudar et al. 2009 [20] & 50 & 28.1 & $\begin{array}{l}\text { Normal/sensorineural } \\
\text { hearing loss }\end{array}$ & $\begin{array}{l}\text { Gender influence, }>\text { absolute latencies and } \\
\text { intervals in male gender. Without relation to age. }\end{array}$ \\
\hline Dabrowski et al. 2011 [25] & 31 & 29.1 & normal & $\begin{array}{l}\text { Absolute latencies of wave } \mathrm{V} \text { and } \mathrm{I}-\mathrm{V} \text { intervals }>\text {; } \\
\text { negative correlation between duration of disease } \\
\text { and absolute latency V and intervals I-V; without } \\
\text { relation to retinopathy. }\end{array}$ \\
\hline Ottaviani et al.2002 [26] & 60 & 31 & normal & $\begin{array}{l}\text { Absolute latencies >; without correlation to age, } \\
\text { duration of disease, insulin, } \mathrm{Hb} \text {, and retinopathy; } \\
\text { correlation to neuropathy. }\end{array}$ \\
\hline Lisowska et al. 2001 [5] & 42 & 33 & normal & $\begin{array}{l}\text { Time latencies and intervals }>\text {; without } \\
\text { correlation with microangiopathy. }\end{array}$ \\
\hline
\end{tabular}


Hypoglycemia alters performance in tests of general mental abilities [32-34], presenting variable sensitivity in accordance with cerebral function, however little is known of its effect in specific cerebral processes. With regard to processing auditory information, it is possible to confirm that hypoglycemia can interrupt short term auditory storage and slow the speed at which the brain is capable of processing obtained information [32,35,36]. Following this, early diagnosis of auditory alterations resulting from type $1 \mathrm{DM}$ is very important, because these central alterations can result in difficulty of sound comprehension and further can compromise the acquisition of auditory abilities (auditory processing), which is responsible for success of verbal communication. Further, considering that type $1 \mathrm{DM}$ occurs mainly in children who do not yet possess established auditory abilities, understanding this process becomes even more important, in order to implement preventative measures and early therapies.

\section{CONCLUSION}

The findings of this review demonstrate that patients with type $1 \mathrm{DM}$ can have auditory alterations stemming from a central cochlear origin.

\section{ACKNOWLEDGEMENTS}

This article is part of the Luciene Fernandes' $\mathrm{PhD}$ Thesis of Bahiana School of Medicine and Public Health Postgraduate Course.

\section{REFERENCES}

[1] American Diabetes Association (2010) Diagnosis and classification of diabetes mellitus. Diabetes Care, 33, S67-69. doi:10.1186/1471-2458-11-564

[2] Hall, V., Thomsen, R., Henriksen, O. and Lohse, N. (2011) Diabetes in sub saharan Africa 1999-2011: Edpidemiology and public health implications-A systematic review. BMC Public Health, 11, 564.

[3] Tufano, A., Cimino, E., Di Minno, M.M.D., Ierano, P., Marrone, E., Strazzullo, A., Di Minno, G. and Cerbone, A.M. (2011) Diabetes mellitus and cardiovascular prevention: The role and the limitations of currently available antiplatelet drugs. International Journal of Vascular Medicine, 2011, 1-5.

[4] Brender, E., Burke, A.E. and Glass, R.M., (2006) Audiometry. Journal of the American Medical Association (JAMA), 295, 460. doi:10.1001/jama.295.4.460

[5] Lisowska, G., Namyslowski, G., Morawski, K. and Strojek K. (2001) Early identification of hearing impairment in patients with type 1 diabetes mellitus. Otology \& Neurotology, 22, 316-320. doi:10.1097/00129492-200105000-00008

[6] Maia, C.A.S. and Campos, C.A.H. (2005) Diabetes mellitus como causa de perda auditiva. Revista Brasileira
De Otorrinolaringologia, 71, 208-214.

[7] Kakarlapudi, V., Sawyer, R. and Staecker, H. (2003) The effect of diabetes on sensorioneural hearing loss. Otology \& Neurotology, 24, 382-386. doi:10.1097/00129492-200305000-00006

[8] Kariya, S., Cureoglua, S., Fukushimad, H., Moritad, N., Baylanc, M.Y., Maedab, Y., Nishizakib, K. and Paparella, M.M. (2010) Comparing the cochlear spiral modiolar artery in type-1 and type- 2 diabetes mellitus: A human temporal bone study. Acta Medica Okayama, 64, 375383.

[9] Cullen, J.R. and Cinnamond, M.J. (1993) Hearing loss in diabetics. Journal of Laryngology \& Otology, 107, 179182.

[10] Celik, O., Yalcin, S., Celebi, H. and Oztürk, A. (1996) Hearing loss in insulin-dependent diabetes mellitus. Auris Nasus Larynx, 23, 127-132.

[11] Bainbridge, K.E., Hoffman, H.J. and Cowie, C. (2008) Diabetes and hearing impairment in the United States: Audiometric evidence from the national health and nutrition examination survey, 1999 to 2004. Annals of Internal Medicine, 149, 1-10.

[12] Elamin, A., Fadlallah, M. and Tuevmo, T. (2005) Hearing loss in children with type 1 diabetes. Indian Pediatrics, 42, 15-21.

[13] Gawron, W., Pospiech, L., Noczynska, A. and Koziorowska, E. (2004) Sudden hearing loss as a first complication of long-standing Type 1 diabetes mellitus: A case report. Diabetic Medicine, 21, 96-98. doi:10.1046/j.1464-5491.2003.01067.x

[14] Kemp, D.T., Ryan, S. and Bray, P. (1990) A guide to the effective use of otoacustic emissions. Ear and Hearing, 11, 93-100. doi:10.1097/00003446-199004000-00004

[15] Ugur, A.K., Kemaloglu, Y.K., Ugur, M.B., Gunduz, B., Saridogan, C., Yesilkaya, E., Bideci, A., Cinaz, P. and Goksu, N. (2009) Otoacoustic emissions and effects of contralateral white noise stimulation on transient evoked otoacoustic emissions in diabetic children. International journal of Pediatric Otorhinolaryngology, 73, 555-559. doi:10.1016/j.ijporl.2008.12.002

[16] Lisowska, G., Namyslowski, G., Morawski, K. and Strojek, K. (2001) Cochlear dysfunction and diabetic microangiopath. Scandinavian Audiology, 30, 199-203.

[17] Fukushima, H., Cureoglu, S., Schachern, P.A., Kusunoki. T., Oktay, M.F., Fukushima, N., Paparella, M.M. and Harada, T. (2005) Cochlear changes in patients with type 1 diabetes mellitus. Otolaryngology-Head and Neck Surgery, 133, 100-106. doi:10.1016/j.otohns.2005.02.004

[18] Erdem, T., Ozturan, O., Miman, M.C., Ozturk, C. and Karatas, E. (2003) Explorations of the early auditory effects of hyperlipoproteinemia and diabetes mellitus using otoacustics emissions. European Archives of Otorhinolaryngology, 260, 62-66.

[19] Fernandes, L.C. and Santos-Momensohn, T.M. (2009) Tinnitus and normal hearing: A study on the transient otoacoustic emissions suppression. Brazilian Journal of 
Otorhinolaryngology, 75, 414-419. doi:10.1590/S1808-86942009000300017

[20] Pudar, G., Vlaski, L., Filipović, D. and Tanackov, I. (2009) Correlation of hearing function findings in patients suffering from diabetes mellitus type 1 in regard to age and gender. Medicinski Pregled, 62, 395-401. doi:10.2298/MPNS0910395P

[21] Park, M.S., Park, S.W. and Choi, J.H. (2001) Distortion product otoacoustic emissions in diabetics with normal hearing. Scandinavian Audiology, 30, 148-115. doi:10.1080/010503901300007362

[22] Di Nardo, W., Ghirlanda, G., Paludetti, G., Cercone, S., Saponara, C., Del Ninno, M., Girolamo S.D., Magnani, P. and Di Leo, M.A.S. (1998) Distortion-product otoacoustic emissions and selective sensorineural loss in IDDM. Diabetes Care, 21, 1317-1321. doi:10.2337/diacare.21.8.1317

[23] Alborch, M.O., Morant, V.A., García, C.J., Pérez, D.V.B., Lorente, R. and Marco A.J. (1998) The study of otoacoustic emissions in diabetes mellitus. Acta Otorrinolaringology, 49, 25-28.

[24] Di Leo M.A.S., Di Nardo, W., Cercone, S., Ciervo, A., Lo Monaco, M., Greco, A.V., Paludetti, G. and Ghirlanda, G.L. (1997) Cochlear Dysfunction in IDDM patients with subclinical peripheral neuropathy. Diabetes Care, 20, 824-828. doi:10.2337/diacare.20.5.824

[25] Dabrowski, M., Mielnik-Niedzielska, G. and Nowakowski, A. (2011) Involvement of the auditory organ in type 1 diabetes mellitus. Journal of Endocrinology, 62, 138-144.

[26] Ottaviani, F., Dozio, N., Neglia, C.B., Riccio, S. and Scavini, M. (2002) Absence of otoacoustic emissions in insulin-dependent diabetic patients. Is there evidence for diabetic cochleopathy? Journal of Diabetes and Its Complications, 16, 338-343. doi:10.1016/S1056-8727(01)00224-0

[27] Seidl, R., Birnbacker, R., Hauser, E., Bernert, G., Freilinger, M. and Schober, E. (1996) Brainstem auditory evoked potentials and visually evoked potentials in young patients with IDDM. Diabetes Care, 19, 1220-1224. doi:10.2337/diacare.19.11.1220
[28] Tóth, F., Várkonyi, T.T., Rovó, L., Lengyel, C., Légrády, P., Jóri, J., Czigner, J. and Kiss, J.G. (2003) Investigation of auditory brainstem function in diabetic patients. International Tinnitus Journal, 9, 84-86.

[29] Durmus, C., Vetiser, S. and Durmus, O. (2004) Auditory brainstem evoked responses in insulindependent (ID) and non-insulin-dependent (NID) diabetic subjects with normal hearing. International Journal of Audiology, 43, 29-33. doi:10.1080/14992020400050005

[30] Niedzielska, G. and Katska, E. (1998) ABR disturbances in children with insulin dependent diabetes mellitus. International Journal of Pediatric Otorhinolaryngology, 44, 1-4. doi:10.1016/S0165-5876(98)00017-2

[31] Pessin, A.B.B, Martins, R.H.G., Pimenta, W.P., Simões, A.C.P., Marsiglia, A. and Amaral, A. (2008) Auditory evaluation in patients with type 1 diabetes. The Annals of Otology, Rhinology \& Laryngology, 117, 366-370.

[32] McCrimmon, R.J., Deary, I.J. and Frier, B.M. (1997) Auditory information processing during acute insulininduced hypoglycaemia in non-diabetic human subjects. Neuropsychology, 35, 1547-1553.

[33] Hannoen, R., Tupola, S., Ahonen, T. and Riikonen, R. (2003) Neurocognitive functioning in children with type-1 diabetes with and without episodes of severe hypoglycaemia. Developmental Medicine \& Child Neurology, 45, 262-268. doi:10.1111/j.1469-8749.2003.tb00341.x

[34] McAulay, V., Deary, I.J., Sommerfield, A.J. and Frier, B.M. (2006) Attentional functioning is impaired during acute hypoglycaemia in people with type 1 diabetes. Diab Medical, 1, 26-31. doi:10.1111/j.1464-5491.2005.01795.x

[35] Strachan, M.W.J., Ewing, F.M.E., Frier, B.M., Mccrimmon, R.J. and Deary, I.J. (2003) Effects of acute hipoglycaemia on auditory information processing in adults with type I. Diabetology, 46, 97-105.

[36] Cooray, G.K., Maurex, L. and Brismar, T. (2008) Cognitive impairment correlates to low auditory event-related potential amplitudes in type 1 diabetes. Psychoneuroendocrinology, 33, 942-950. doi:10.1016/j.psyneuen.2008.04.013 